(6)

\title{
Functional microperimetry and SD-OCT confirm consecutive retinal atrophy from optic nerve pit
}

This article was published in the following Dove Press journal:

Clinical Ophthalmology

10 November 2009

Number of times this article has been viewed

\section{Vikram S Brar \\ Ravi K Murthy \\ KV Chalam}

University of Florida College of Medicine, Department of Ophthalmology, Jacksonville, FL, USA
Correspondence: KV Chalam University of Florida, Department of Ophthalmology, 580 West 8th Street, Tower II, 3rd Floor, Jacksonville, FL 32209, USA

Email kchalam@jax.ufl.edu

\begin{abstract}
A congenital anomaly, optic nerve pit is often associated with serous retinal detachment involving macula. Long standing serous detachment leads to outer retinal atrophy and decrease in visual sensitivity. Recently, spectral-domain optical coherence tomography (OCT) has been reported to demonstrate a communication between the optic nerve sheath and the subretinal space. Vitreous cavity is proposed as an alternate source of fluid for accumulation in the subretinal space. We imaged a patient with optic nerve pit with Spectralis OCT and report the findings seen including the presence of an area of peripapapillary retinal atrophy, due to the spontaneous resolution of associated long-standing retinal detachment.
\end{abstract}

Keywords: optic nerve pit, SD-OCT, autoflourescence, microperimetry

\section{Introduction}

A congenital anomaly, optic nerve pit is often (50\%) associated with serous retinal detachment which can lead to vision loss over time. ${ }^{1}$ The advent of optical coherence tomography (OCT) has provided evidence in support of a schisis cavity progressing to involve the outer retinal layers in patients with optic nerve pits. ${ }^{2-5}$ Our case report depicts atrophy of the outer retina in a patient with an optic nerve pit highlighted on spectral-domain OCT (SD-OCT) and fundus autoflourescence (FAF) imaging. Functional microperimetry (MP-1) confirmed loss of visual function in the affected area.

\section{Case report}

An 80-year-old male presented for a routine follow up for dry age-related macular degeneration (AMD). Best-corrected visual acuity was stable at 20/30 and 20/40, respectively. Anterior segment examination was significant for pseudophakia OU and otherwise unremarkable. Fundus examination revealed the presence of a temporal optic nerve pit OD (Figure 1), with pigmentary changes and fine drusen in the macula OU.

SD-OCT (Spectralis; Heidelberg Engineering, Heidelberg, Germany) sections through the pit demonstrate excavation in the optic nerve (Figure 2A). In addition, an area of outer retinal atrophy is noted adjacent to the optic nerve pit with preservation at the fovea (Figure 2B). No communication between the pit and the adjacent retina was identified on high resolution scanning. Retinal thickness mapping using automated analysis highlighted an area of retinal thinning that extended inferior temporally from the pit (Figure 3A). Hyperflourescence was present on FAF 


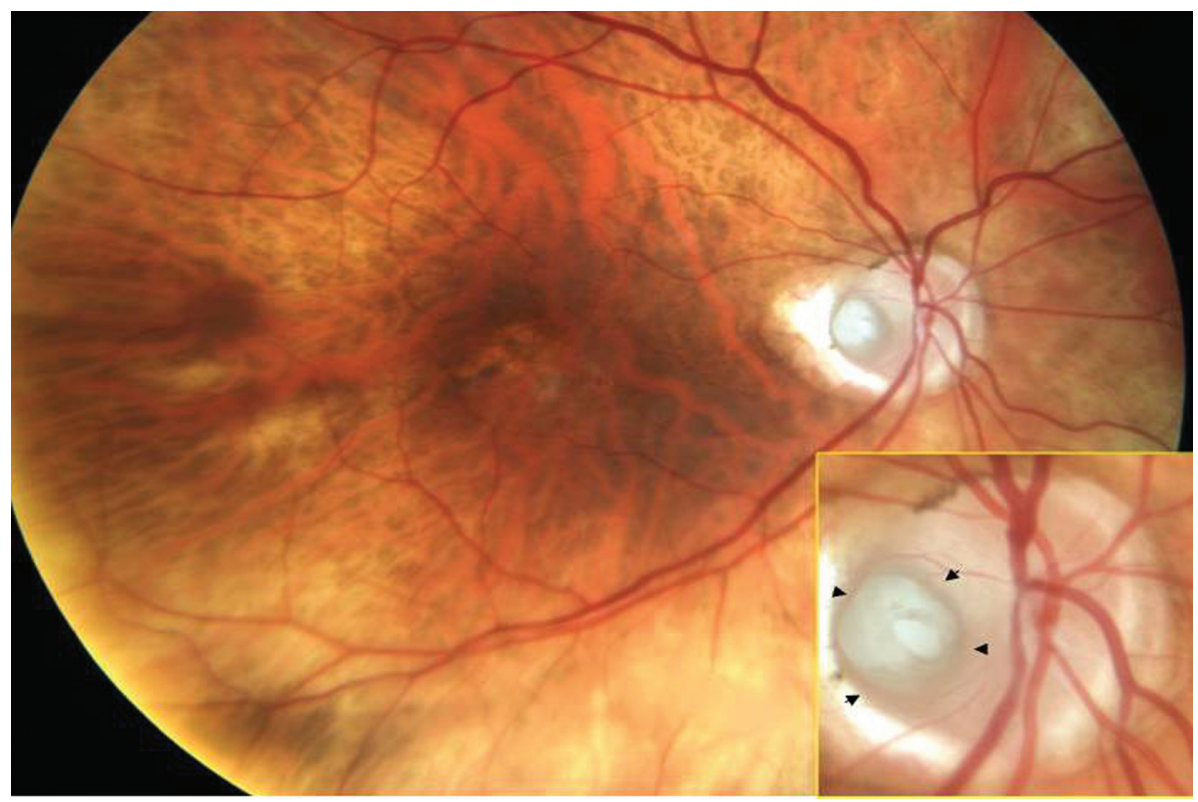

Figure I Color fundus photograph of the right eye, depicting an optic nerve pit with peripapillary atrophy. Mild pigmentary changes are present in the macula. Arrow heads point to the margins of the pit.

(Spectralis; Heidelberg Engineering) imaging in the area of retinal thinning (Figure 3B). MP-1 (Nidek, Gamagori, Japan) revealed significant reduction in threshold in this region, with preserved function at the fovea and sparing of retina superiorly (Figure 3C).

\section{Discussion}

Sixty-three percent of optic nerve pits are temporal with the natural history of associated serous maculopathy resulting in vision loss over time. ${ }^{1}$ In one report, $80 \%$ of patients had a final visual acuity of 20/200 or worse, with

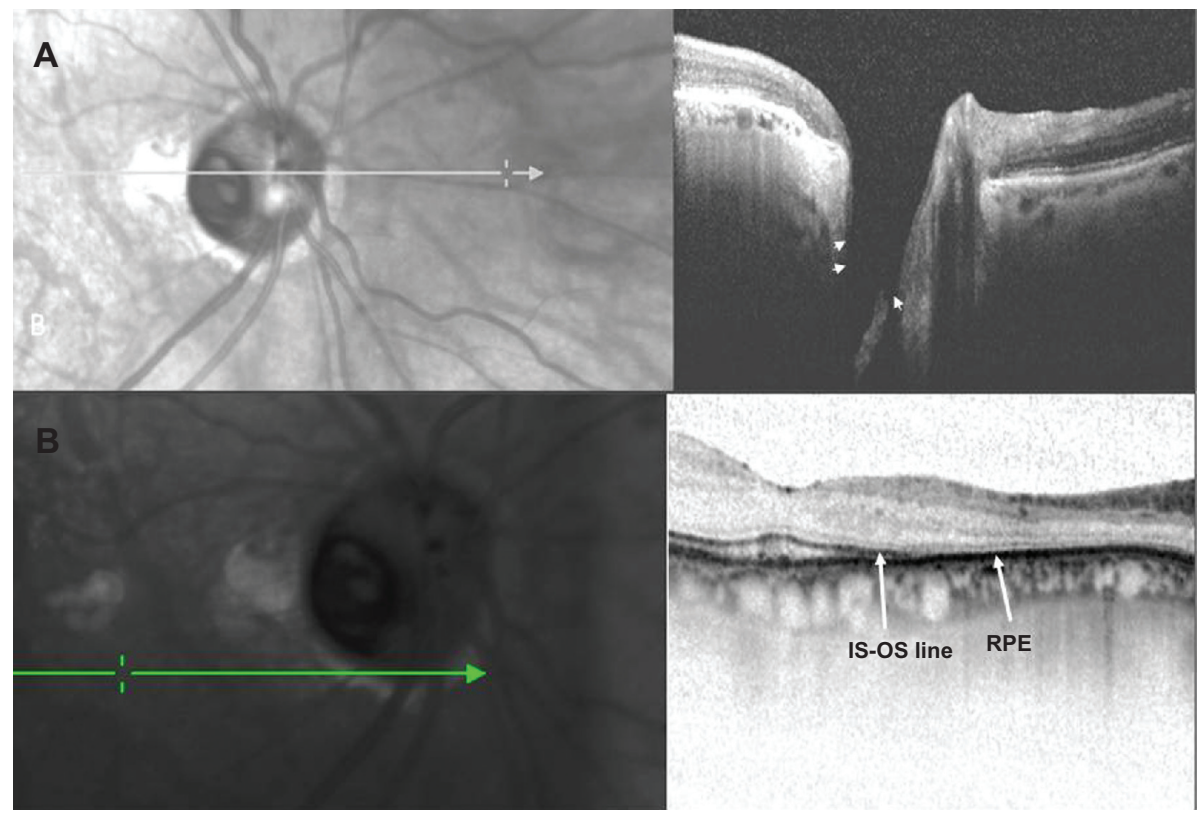

Figure 2 A) Combined infrared imaging and SD-OCT (Spectralis; Heidelberg Engineering, Germany) demonstrate excavation of the optic nerve with an adjacent area of outer retinal atrophy. Arrow heads pointing to the excavation seen on Spectralis OCT. B) Spectralis OCT scan demonstrates loss of the photoreceptor outer segments with preservation of the underlying retinal pigment epithelium. Arrow indicating the point where inner segment-outer segment junction of the photoreceptor becomes discontinues indicating atrophy. RPE is seen as a dark continuous band.

Abbreviations: OCT, optical coherence tomography; RPE, retinal pigment epithelium. 


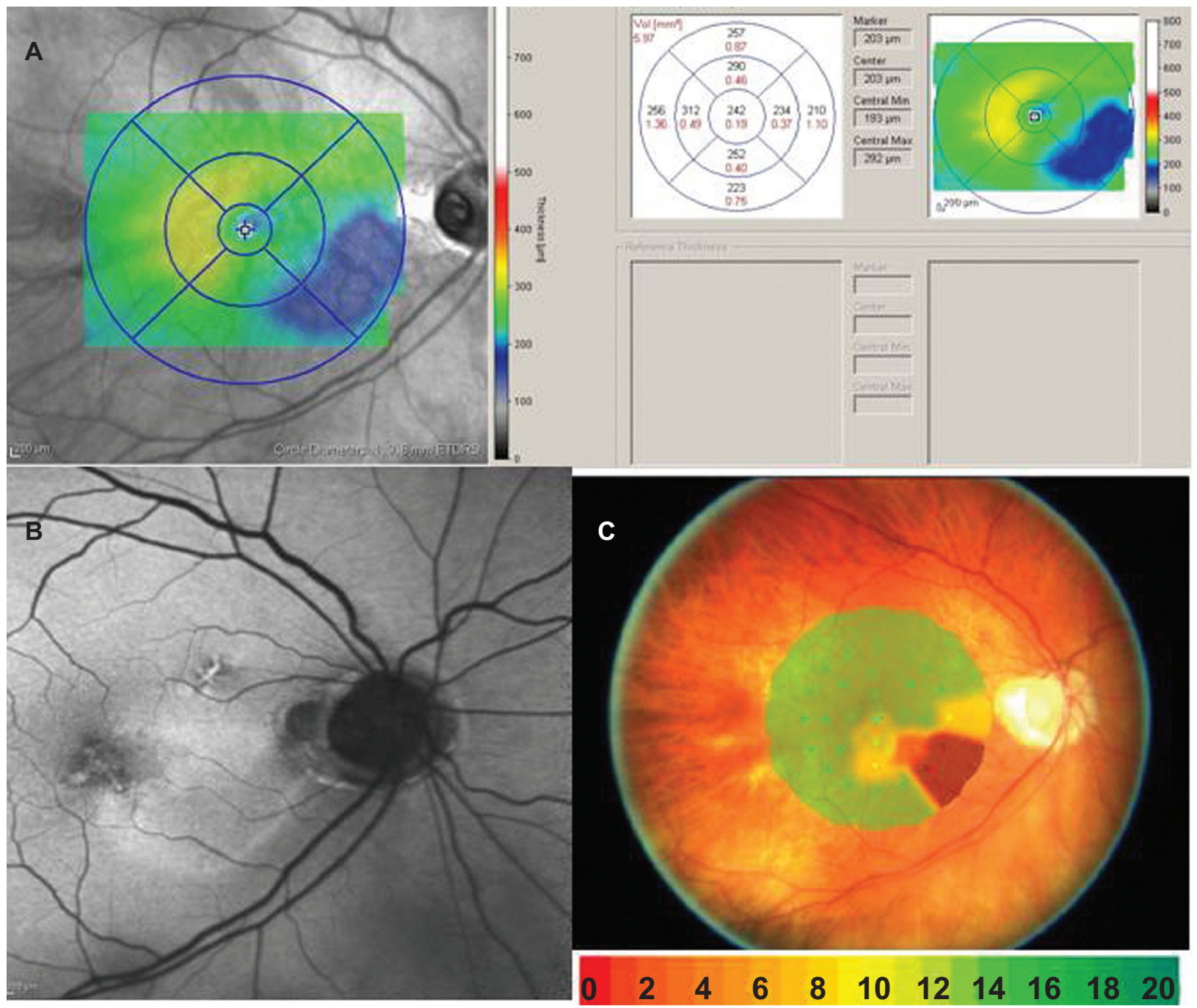

Figure 3 A) Retinal thickness mapping demonstrates thinning of the retina in the paillomacular bundle, extending inferior temporally. B) Fundus autoflourescence shows hyperfluorescence in the area of retinal thinning. C) Microperimetry (MP-I) demonstrates loss of threshold corresponding to the area of thinning. The blue dots are a fixation map of the patient while doing the test. Color codes indicate visual sensitivity in decibels.

an average follow-up of nine years. ${ }^{2}$ Subsequently, OCT findings have illustrated the connection between the serous detachment and optic nerve pit and confirmed the presence of a schisis cavity, which has been proposed to develop secondarily. ${ }^{3-5}$

In our case, Spectralis OCT showed preservation of photoreceptor outer segments at the fovea which correlated with normal threshold values on microperimetry and preserved Snellen visual acuity. Outer retinal thinning, marked by discontinuity of the inner segment-outer segment (IS-OS) line, was seen adjacent to the optic nerve pit, in an area of prior serous detachment. A recent case report describes retinal nerve fiber layer thinning (RNFL) in the papillomacular bundle in a young patient without corresponding changes on Goldman visual field testing. ${ }^{5}$
However, data from MP-1 testing, in our case, confirm the relationship between photoreceptor loss and scotoma development, with preservation of the RNFL in this region.

The source of the schisis fluid has been debated over the years. It has been hypothesized that vitreous is a source of the schisis fluid and vitrectomy has been advocated as a treatment modality to collapse the schisis. ${ }^{67}$ However, in our case, we could not neither demonstrate any vitreous syneresis overlying the pit nor observe any kind of communication between the pit and the subretinal space.

FAF imaging revealed hyperflourescence in the area of the scotoma, indicating the accumulation of lipofuscin. ${ }^{8}$ Spectralis OCT did not demonstrate defects in the underlying retinal pigment epithelium, suggesting the pathology is limited to the retina. 
In conclusion, our report describes consecutive outer retinal atrophy in vivo with corresponding reduction in functional testing but preserved central vision in a patient with an optic disc pit.

\section{Disclosures}

The authors report no conflicts of interest in this work.

\section{References}

1. Sobol WM, Blodi CF, Folk JC, Weingeist TA. Long-term visual outcome in patients with optic nerve pit and serous retinal detachment of the macula. Ophthalmology. 1990;97(11):1539-1542.

2. Krivoy D, Gentile R, Liebmann JM, et al. Imaging congenital optic disc pits and associated maculopathy using optical coherence tomography. Arch Ophthalmol. 1996;114(2):165-170.

3. Lincoff H, Schiff W, Krivoy D, Ritch R. Optic coherence tomography of optic disk pit maculopathy. Am J Ophthalmol. 1996;122(2):264-266.
4. Schneider M, Geitzenauer W, Ahlers C, Golbaz I, Schmidt-Erfurth U. Three-dimensional imaging of an optic disk pit using high resolution optical coherence tomography. Eur J Ophthalmol. 2009;19(2): 321-323.

5. Meyer CH, Rodrigues EB, Schmidt JC. Congenital optic nerve head pit associated with reduced retinal nerve fibre thickness at the papillomacular bundle. Br J Ophthalmol. 2003;87(10):1300-1301.

6. Hirakata A, Okada AA, Hida T. Long-term results of vitrectomy without laser treatment for macular detachment associated with an optic disc pit. Ophthalmology. 2005;112(8):1430-1435.

7. Georgalas I, Petrou P, Koutsandrea C, Papaconstadinou D, Ladas I, Gotzaridis E. Optic disc pit maculopathy treated with vitrectomy, internal limiting membrane peeling, and gas tamponade: a report of two cases. Eur J Ophthalmol. 2009;19(2):324-326.

8. Schmitz-Valckenberg S, Fleckenstein M, Göbel AP, et al. Evaluation of autofluorescence imaging with the scanning laser ophthalmoscope and the fundus camera in age-related geographic atrophy. Am J Ophthalmol. 2008;146(2):183-192.
Clinical Ophthalmology

\section{Publish your work in this journal}

Clinical Ophthalmology is an international, peer-reviewed journal covering all subspecialties within ophthalmology. Key topics include: Optometry; Visual science; Pharmacology and drug therapy in eye diseases; Basic Sciences; Primary and Secondary eye care; Patient Safety and Quality of Care Improvements. This journal is indexed on

\section{Dovepress}

PubMed Central and CAS, and is the official journal of The Society of Clinical Ophthalmology (SCO). The manuscript management system is completely online and includes a very quick and fair peer-review system, which is all easy to use. Visit http://www.dovepress.com/ testimonials.php to read real quotes from published authors. 